\title{
Automotive Sheet Metal SAPH440 and Q235 Formability of Comparative Study
}

\author{
Ming-Liang $\mathrm{LI}^{1, \mathrm{a}}$, Da-Sen $\mathrm{BI}^{2, \mathrm{~b}}$, Jun-Ke $\mathrm{HAO}^{3, \mathrm{c}}$ \\ 1,2,3 Tianjin University of Technology, TianJin, China \\ alimingliang0414@163.com, btjbds@sina.com, 617740689@qq.com
}

Keywords: Automotive sheet metal, Comparative study, Formability.

\begin{abstract}
SAPH440 and Q235 these two materials are automotive sheet metal,through the experiment on mechanical properties, microstructure and bulge forming ability have a comparative study between them. The experimental results showed that: SAPH440 mechanical performance is better than that of Q235, it has small, uniform microstructure grain and strong bulge forming ability. This suggests that the forming performance of SAPH440 is better than Q235. With the rapid development of automobile industry, The design concept of "safety, environmental protection, energy saving" for cars with material and forming technology is put forward higher requirements[1]. Sheet metal forming technology mainly includes the separation process and plastic deformation process, Separation process is a part of the material is separated from the whole or partial separation, Mainly including blanking, punching and trimming, cutting, etc, The plastic deformation process is the external force is applied to deform the material to achieve the desired shape, Mainly including stretching, bending, twisting, curling, spinning, flanging, bulging, etc. Automotive sheet metal formability is refers to the board's ability to adapt to forming technology, formability of sheet metal forming process directly affects productivity, product quality and production costs. Automotive sheet metal formability is related to the forming process, and related to the material of the indicators. Under the condition of process conditions are relatively stable, forming quality depends largely on the performance of the material, So the automotive sheet metal forming performance index is very important[2]. In this paper,there has a comparative study on mechanical performance, organization performance, shape deformation, bulging between automotive sheet metal SAPH440 and Q235 through experiment, it provide experimental evidence for automotive sheet metal stamping process.
\end{abstract}

\section{Experiment}

\section{Experiment Materials}

Experiment material used SAPH440 and Q235, their thickness are 2.0mm, their chemical composition as shown in Table 1[3].

Tab. 1 SAPH440 and Q235 chemical composition (w)\%

\begin{tabular}{|c|c|c|c|c|c|c|}
\hline $\begin{array}{c}\text { Type of } \\
\text { material }\end{array}$ & $\mathrm{C}$ & $\mathrm{Si}$ & $\mathrm{Mn}$ & $\mathrm{P}$ & $\mathrm{S}$ & Als \\
\hline SAPH440 & 0.21 & 0.3 & 1.5 & 0.03 & 0.025 & 0.01 \\
\hline Q235 & 0.22 & 1.4 & 0.35 & 0.045 & 0.05 & - \\
\hline
\end{tabular}

\section{Experiment Methods}

At room temperature, according to the national standard, intercept each test sample, in WDW-10 type microcomputer control electronic universal testing machine for uniaxial tensile test, in the GBS-60 type display semi-automatic cup drawing experiment was carried out on board, with BX51M type electron microscope to observe the microstructure .

\section{The Experiment Result Analysis}

\section{Mechanical Properties Analysis}

Through the treatment for the data from unidirectional tensile test, you can get two material stress-strain curve, as shown in figure 1. 


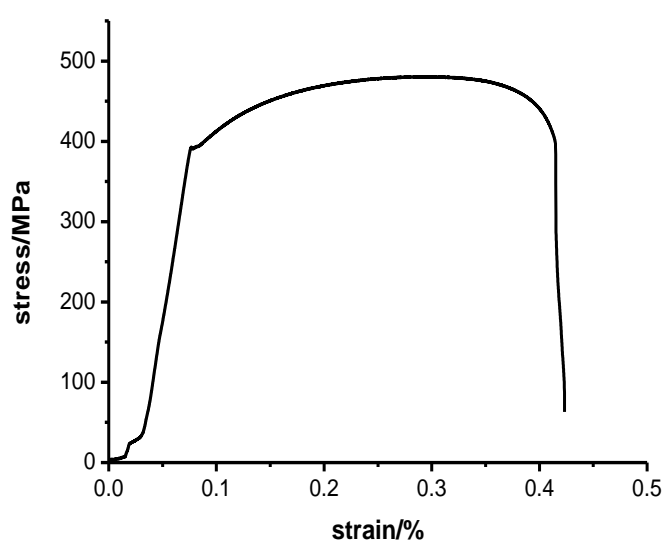

(1)SAPH440 stress-strain curve

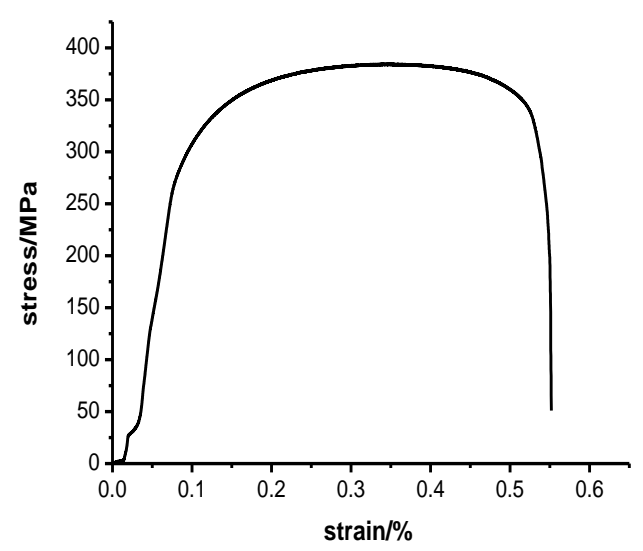

(2)SAPH440 stress-strain curve

Fig.1 stress-strain curve

Mechanical properties can be obtained through these two materials test data, their mechanical properties of parameters in Table 2.

Tab. 2 SAPH440 and Q235 mechanical performance parameters

\begin{tabular}{|c|c|c|c|c|c|c|c|}
\hline $\begin{array}{c}\text { Type of } \\
\text { material }\end{array}$ & Thickness $(\mathrm{mm})$ & $\begin{array}{c}\text { Yield } \\
\text { Strength } \\
(\mathrm{MPa})\end{array}$ & $\begin{array}{c}\text { Tensile } \\
\text { strength } \\
(\mathrm{MPa})\end{array}$ & $\begin{array}{c}\text { Strain } \\
\text { hardening } \\
\text { index n }\end{array}$ & $\begin{array}{c}\text { Plastic } \\
\text { strain } \\
\text { ratio r }\end{array}$ & $\begin{array}{c}\text { Yield } \\
\text { ratio }\end{array}$ & $\begin{array}{c}\text { Elongation } \\
(\%)\end{array}$ \\
\hline SAPH440 & 2.0 & 315 & 490 & 0.170 & 1.23 & 0.643 & 33.3 \\
\hline Q235 & 2.0 & 270 & 390 & 0.135 & 1.27 & 0.692 & 30.4 \\
\hline
\end{tabular}

Through the analysis of test data can be qualitative comparison of these two kinds of experiment materials forming performance, from Figure 1 and Table 2, SAPH440 yield strength and tensile strength, respectively, higher than the Q235 45MPa and 100MPa, elongation also bigger than Q235, strain hardening index is higher than that of Q235.

Strain hardening index $\mathrm{n}$ value can be used as measuring materials tensile plastic deformation phase of the strain hardening ability of a parameter. It describes the features and the degree of hardening of the material, it is a direct measure of material stretching. The greater $n$ value of material, the more obvious of work hardening, the strain uniformity is the better. The greater of SAPH440's n value shows that it is not easy to enter the unstability of the dispersion, strain hardening has a strong ability, forming performance is good.

Plastic strain ratio $r$ values are important parameters for evaluating sheet metal deep drawing properties. It is a thin metal sheet to uniaxial stretching to the sample when a uniform plastic deformation, within the specimen gage length, width of true strain epsilon $\varepsilon_{\mathrm{b}}$ and true strain epsilon $\varepsilon_{\mathrm{a}}$ ratio of the thickness direction, $\mathrm{r}=\varepsilon_{\mathrm{b}} / \varepsilon_{\mathrm{a} . .}$. The $\mathrm{r}$ value of SAPH440 and Q235 have little difference, This shows that they are roughly the same ability to resist buckling of thin.

Yield ratio is the ratio of the yield strength and tensile strength. The low of yield ratio shows the plasticl of the materia is better. SAPH440 has a lower yield ratio than Q235, it is shows that SAPH440 processing complex parts more easily.

Elongation is the ratio of the length of the original length and the test piece elongated.it is an important indicator of material plasticity. SAPH440's elongation is larger than Q235 shows its plasticity is better[5].

\section{Morphology Studies}

Etching samples with $4 \%$ nitric acid alcohol solution, and use the electron microscope to observe the microstructure shown in Figure 2. 


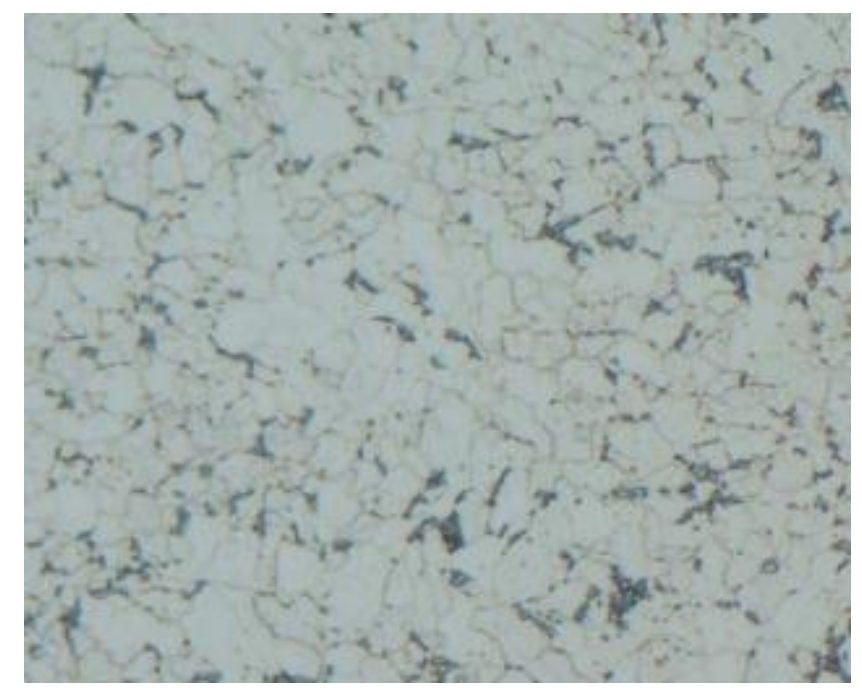

(1)SAPH440 microstructure photo

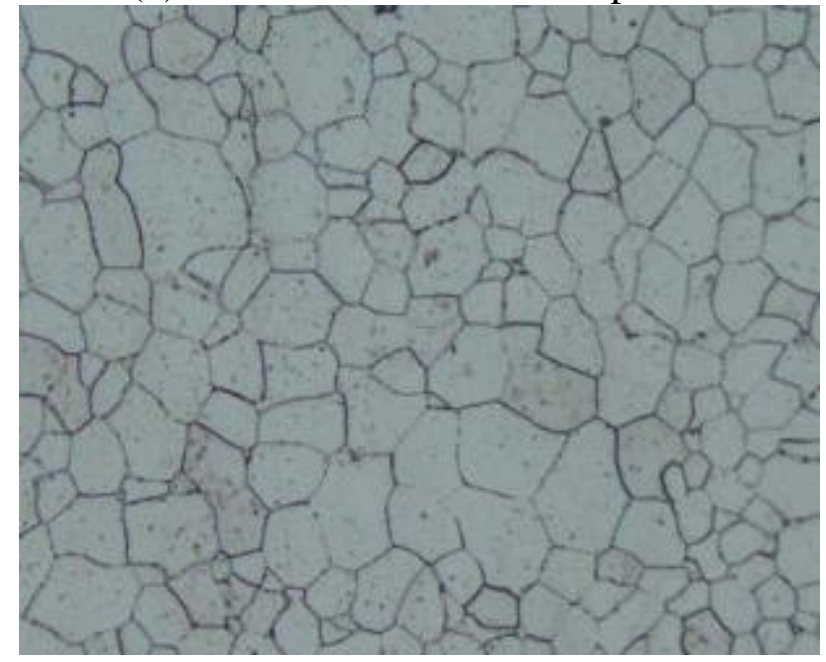

(2)Q235 microstructure photo

Fig.2 Microstructure(500 times)

As can be seen from the microstructure photos, SAPH440's microstructure is ferrite and fine pearlite, no obvious banded structure, ferrite grains is fine and uniform, there is no mixed crystal tissue on surface, and this ensure it has good strength and elongation. The microstructure of Q235 is ferrite and pearlite, compared with SAPH440's microstructure, grain is bulky and uneven, this caused it has not better mechanical properties than SAPH440.

\section{Cup Drawing Experiment Results Analysis}

Cup drawing experiment is a test sheet metal forming ability to adapt to the limits of auxetic, experiment using the punch for the spherical end of pressure to press the pressure of the sample into membrane, until appear through the crack, as the cup drawing depth measured test results[6]. Through the experiment measured the cup drawing of SAPH440 value is $12.29 \mathrm{~mm}$, Q235 cup drawing of value is $12.15 \mathrm{~mm}$, that means SAPH440 bulge forming ability is stronger than Q235.

\section{The Actual Production Situation}

During Tianjin jinzhao mechanical and electronics development Co. Ltd producting a automobile steering column mounting plate, begin to use Q235 production of the product, due to the product process is relatively complex, there are punching, flanging and bending process, there have cracks , fracture phenomenon with Q235, the product does not meet customer requirements. Finally use SAPH440 production the product, produced products as shown in figure 3, products not only have no cracks and fracture phenomenon, but also in terms of mechanical properties can meet customer requirements, and achieve significant economic and social benefits. 


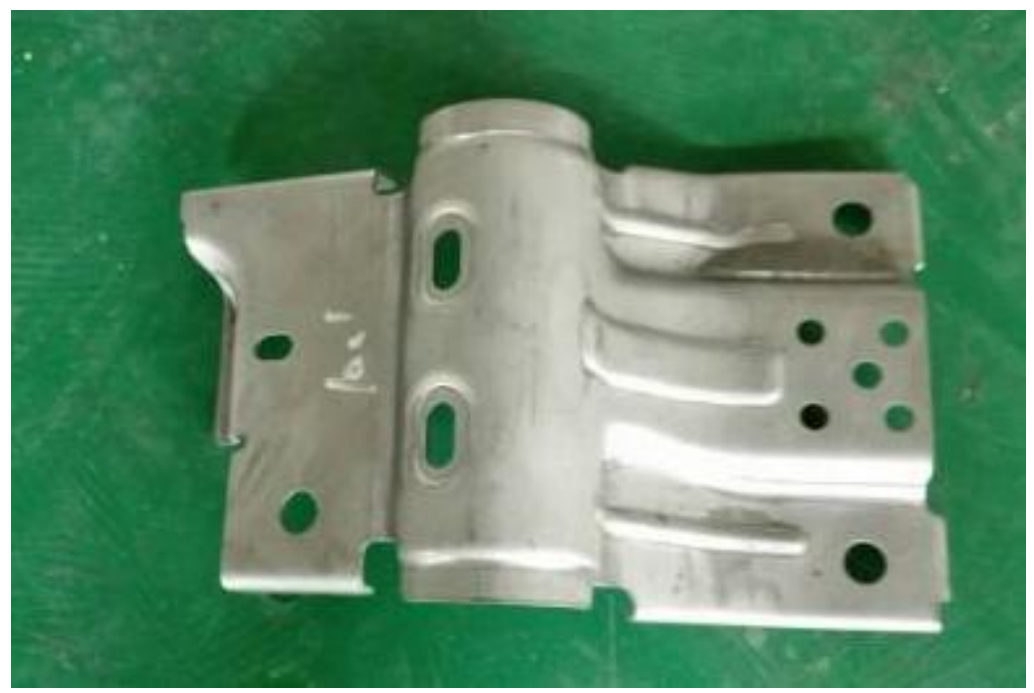

Fig. 3 a automobile steering column mounting plate

\section{Conclusion}

(1) SAPH440 has high tensile strength and yield strength, excellent elongation, low yield ratio, good cold formability characteristics and surface quality compared with Q235 .

(2) SAPH440 metallographic organizations is small ferrite and pearlite, fine grains, so from the internal organization to explain the SAPH440 has the characteristics of excellent mechanical properties than Q235 .

(3) In actual production application, SAPH440 mainly applied in the production of complex deformation on automobile parts, meet customer requirements, and create significant economic and social benefits.

\section{Acknowledgement}

This research was 2013 Tianjin Science and Technology Support Program.

\section{References}

[1] Yao Guisheng,Jing Liyuan. Automotive Steel Application Technology[M].BeiJing: Mechanical Industry Press,2008.

[2] Liu Ze et al. Research on the Effects of Material Properties in Sheet Forming[J]. Automotive Technology,1996,(10).

[3] Wu Juhuan. Automobile Structure with SAPH440 Hot Rolled Steel Plate Trial-produced[J]. Steel Rolling,2001,28,(1):63-67.

[4] Liu Hongwen. Mechanics of Materials, (4th edition), Higher Education Press,2004.

[5] Tan Shanhun et al. Experimental Study Classification Sheet Stamping[J]. Automotive Technology,1992,(5).

[6] GB/T4165-1984, Metal Cupping Experiment methods[s]. 